This is an Accepted Manuscript of an article published by Taylor \& Francis in International Journal of Inclusive Education on 30/01/18, available online:

http://www.tandfonline.com/10.1080/13603116.2018.1427150.

\title{
Building Inclusion and Resilience in Students with and without SEN through the Implementation of Narrative Speech, Role-play and Creative Writing in the Mainstream Classroom of Primary Education
}

Elena Vitalaki, Elias Kourkoutas and Angie Hart

Department of Primary Education, Rethymno, Crete, Greece* University of Brighton, $U K$

Corresponding author: vitalakielena@gmail.com

Elena Vitalaki, PhD, Teaching Staff, University of Crete,

Elias Kourkoutas, Professor, University of Crete, Greece

Angie Hart, Professor, University of Brighton, UK 


\section{Abstract}

Based on the theory of inclusion, the present 3-year pilot program (20132016) deals with narrative speech, role-play and creative writing as a useful tool to build resilience in primary school students with and without SEN in the mainstream classroom. The specific aim of the program was to help students develop a series of fundamental psychosocial skills, such as a positive sense of inner-self and self-awareness, the ability to cooperate and relate to the others by familiarizing with them in recognizing and expressing the basic emotions of joy, sadness, fear and anger.

Under the systematic cooperation among the general education teacher, the special education teacher and the rest of the teaching staff- the concept was to involve the maximum of the school teachers in order to create a Community of Practice, Collaboration, Sharing Learning and Action. Using an action-based research approach including notes, observation and video analysis of the activities, interactions and attitudes towards the program, the data from the present work allowed the participating students to demonstrate a range of socio-emotional skills, including those necessary for self-awareness, respect to others, critical and creative thinking. Similarly, the 5 teachers (drama teacher, art teacher, the teachers of general and special education and the school director) involved in the project in each class, built positive relations with their students and the rest of the teachers as well, whom they encouraged to participate in various collaborative tasks through similar programs.

Keywords: Narration; role-play; creative writing; building inclusion and resilience; community of practice; mainstream primary class 


\section{Introduction}

Due to the coexistence/mainstreaming of students with SEN in the regular classroom of primary school, the promotion of a climate (culture) of mutual understanding, collaboration and empathy (among students, teachers, and between teachers and families) is the central scope of the resilience and inclusion theoretical aspects (Kourkoutas, Vitalaki and Fowler, 2015).

Whilst resilience building involves complex socio-ecological processes, one aspect of that is supporting the individual's ability to resist and overcome the presence of critical factors or stressful events, coming out stronger and more aware of their own resources (Khalnou and Wray, 2014; Makoelle and Malindi, 2015). The promotion of inclusion within the mainstream classroom helps students develop their learning abilities and psychosocial skills in a collaborative and interactive climate. This usually leads to the facilitation of academic and emotional resilience and acceptance especially for those at-risk students (Ainscow, Dyson, Goldrick and West, 2012).

Narrative speech, role-play and creative writing can be used as a meaningful practice for the educational and social inclusion of vulnerable students as they learn to develop their interpersonal and academic skills through common educational and childcentred cooperative/collaborative actions. These practices give students the opportunity to experiment without fear of failure, the construction of new skills and experience new aspects of themselves and new identities (Stockwell, 2016; Vygotsky, 1978; Waters, Barsky, Ridd and Allen, 2015). The implementation of such programs in the mainstream primary classroom are consistent with the Community of Practice (CoP) approach as it encourages a different/diverse group of students to work collectively and develop mutual/active engagement in a shared repertoire of activities/interests/experiences (Ferguson, 2012; Wenger, 2006). Such programs allow 
all students and especially those with SEN to collaborate fruitfully and learn cooperatively from one another as they can get involved with students from other classes and the rest of the teaching staff. (Authors, 2015; Waters et al. 2015; Zins and Elias, 2006).

In the present study, narrative speech, role-play and creative writing became a dynamic process, often referred to by Kolb $(1984,38)$ as (an/a) experiential learning/ transformation experience on the basis of collaborative creativity in the mainstream classroom of primary school. A further aim was to contribute to the development of emotional and educational skills of at-risk students concerning the use of effective group work in school-based collaborative, interactive and creative writing activities (Fagan, 2010; Stockwell, 2016).

\section{Theoretical background}

Research shows that the more schools support the social and emotional needs of students the smoother and more progressive is the inclusion of those with SEN in a regular classroom as children cultivate a spirit of respect towards diversity and a sense of mutual understanding and acceptance (Waters et al. 2015; Zins and Elias, 2006). Nonetheless, many teachers face difficulties in encouraging learning and creativity in students with SEN probably because they are unable to abandon a medical vision of these children's problems and adopt a holistic view of the child's difficulties (Kourkoutas, Vitalaki and Fowler, 2015). So, most of the them in the general class continue to focus on cultivating and measuring the traditional academic skills and attainment which are usually reductive, restrictive and above all alienating to many students (Zoniou-Sideri and Vlachou, 2006).

The implementation of narration, role-play and creative writing programs in the school curriculum as an intervention technique for students with or without socio- 
emotional problems can: a) be considered a dynamic procedure of active learning (Chan, 2013) and, b) play a vital role in the regulation of developing a better sense of their inner-self (self-awareness) and of understanding and connection to others (Kilgour, Reynaud, Northcote and Shields, 2015; Moore, 2004). Apparently, storytelling, roleplay and creative writing can become a dynamic process, and an experiential learning cycle which highlights that "experience (action) is systematically followed by reflection, learning (review) and experimentation (further action)" (Kolb, 1984, 38). Mentors committed to inclusive and resilience practice attempt to stimulate students' willingness to work creatively and collaboratively (Waters et al. 2015) and teach them how to progress to a more central role as actors and competent participants in their communities of practice over time.

The narration of a story is a very important psychosocial procedure for children as they can learn to express their desires/feelings/ideas and develop a deep sense of themselves, and the behaviours of others through the re-construction of their stories (Bruner, 1997). Students are motivated to trace back their personal interests, to cultivate their imagination, to express their ideas and personal feelings/emotions/identities and to feel satisfaction and contentment.

Role-play, which involves imaginative transformation and reflection on experiences, can help students expand their ability to act out thoughts in their minds (Kilgour et al. 2015). This technique can become a prevailing approach to teach students valuable social skills and offer a more pleasant language-learning experience, creating a "safe environment where learners are relaxed, creative and inventive" (Magos and Politi, 2008, 101-102). It is an intriguing way of encouraging students to create a fictional world in which they assume roles to explore issues that are of great concern to them. By doing so, students are able to learn through other perspectives and 
act as one would in the imagined situation. Above all, using role-play teaches primary students the power to have a key role in their education by connecting to the concept emotionally and having a better understanding of it (Nezami, Barekat and Tahiri, 2017; Shapiro and Leopold, 2012). Also, the production of a written story may become a very effective way of cooperative learning and it offers support during the educational process even to those who cannot learn without closer assistance. Students learn to interact in group activity, to think collectively and engage critically but constructively with each other's ideas which are finally offered for joint consideration (Fagan, 2010).

In conclusion, the practice of narration, role-play and creative writing in the mainstream classroom is consistent to both the philosophy and notion of inclusive education and resilience as they can play a major part in the re-establishment of the academic and socio-emotional aspects of education giving emphasis to the quality of relations among the involved group of people (Kourkoutas, Hart, Graaf and Kassis, W 2017; Putnam, 2009). Cooperation is the key word among the involved persons and requires efforts such as building relations of trust, peer interaction/communication, mutual understanding and acceptance, and constructive problem solving (Putnam, 2009, 90). Finally, the implementation of the above tools in the school curriculum can be used for enabling the setting up of a CoP within the school context (Wenger, 2006). This notion is usually supported by students' engagement as well as the rest of the teaching staff in collaborative tasks by generating enthusiasm, relevance, and value.

\section{General background of the intervention program}

The present 3-year (2013-2016) project was conducted within the framework of socioemotional programs under the auspices of the Greek National Bureau of Education and the department of Primary Education, University of Crete. The participant teachers received ethical approval for the implementation of this intervention program by the 
Primary Education Bureau of Crete in the beginning of each academic year.

Confirmation and participation of the principals of the schools was essential for the insight into methods for organizing the teachers and for the inclusion of children with SEN in mainstream school. Parents were informed of the purpose of the program and the interventions to be used and gave written consent for the use of the data, especially in view of videotaping and photographs of the students' interactions and assignments that were taken. The anonymity of schools and participants was preserved throughout all datasets and research outputs.

The program was implemented in two public primary schools during the years 2013-2016 and was focused on cultivating students' sense of self and communication among peers regarding the pupils' familiarization in identifying and expressing the basic emotions of joy, sadness, fear, anger. Narrative speech, role-play and creative writing (based on children's written stories) were used as innovative tools for the school inclusion and development of psychosocial skills of children with SEN in the mainstream classroom. Emphasis was also given to the formation of Communities of Practice $(\mathrm{CoP})$ within schools through the creation of close collaborations/interactions among pupils and the teachers of general and special education, the art teachers, the drama teachers and the school directors (the idea being to involve the maximum of school staff). Additionally, this approach may be valued for introducing new ways of investigating the relationships and experience among children with or without SEN and of working in an interdisciplinary and partnership perspective in the mainstream classroom.

The overall assessment of the school project aimed at investigating:

- The way the techniques of narration, role-play and creative writing contribute to the empowerment of self-sentiment/emotional expression and improvement of 
the self-image of children with SEN through the development of social and communicative skills with others (peers-teachers).

- The progress of the inclusion of children with SEN in a regular school environment through the implementation of the particular program, and

- The teachers' attitudes towards the implementation of this program through the formation of a collaborative learning environment within the school context.

Research method: Goals, tools and sample

The fundamental goals of the intervention program are as follows:

(1) The creation of a coherent dynamic $\mathrm{CoP}$ with high levels of cooperation and engagement of all students in a common goal through entertaining and meaningful activities such as role-play and the production of a written story.

(2) The promotion of socio-emotional expression through the narration of a personal story (individual production) and role-play in order to write a final common story (collective production).

(3) The progressive inclusion of children with SEN in the general classroom/group and respect of diversity through these activities.

(4) The development of all students' (with and without SEN) psychological/empathetic (resilience) skills as well as self-awareness of their strengths, and

(5) The teaching staff's involvement in this project and their inspiration/willingness to implement similar activities that would change the classroom dynamics and promote all students' academic and social-emotional resilience.

These particular actions were used as tools to achieve the pre-mentioned goals:

- Narration of personal or imaginary stories.

- Role-play based on students' narrations and their written story. 
- Classroom group discussions about selecting their favourite theme, their fantasy heroes and writing about them.

The present program could be termed as an Action Research Intervention project in the sense that it includes a dynamic procedure of data production, data collection and data analysis. The action research approach was chosen because it promotes change at both an individual and an organizational level and gives the opportunity to the involved teachers to reflect on their practice and produce new ways of conceptualizing children's difficulties and school inclusion (McNiff, Lomax and Whitehead, 2003). The present action research approach used a participant observation which focused on numerous individual experiences of the participant teachers who became the observers of shared events, activities or attitudes by becoming members of the groups and thus, better interpret the whole outcome of the program (Goode and Hatt, 1986; Hill, Knox, Thompson, Williams, Hess and Ladany, 2005). In each class, the teacher of general education was responsible for gathering the data which was based on the analysis of: a) their notes, b) the recorded conversations/interactions among students and their teachers, c) the recorded in and out of classroom activities and, d) the participants' observed attitudes and oral statements about the program (Mills, 2003). The way the present program has been implemented and the specific ingredients or used materials show entirely the quality, knowledge, and skills of the educational staff and the particular student group features (O’Hanlon, 2003).

As for the sample, 48 primary students (16 students from each year) of the $2^{\text {nd }}$, $3^{\text {rd }}$ and $4^{\text {th }}$ grades have participated in this program. The average number of pupils in each class was 16, aged between 7 - 9 years old with an even gender balance in all classes. Each year, there were an average number of 5 students diagnosed with SEN (autism, AD/HD and emotional or behavioural problems) in every class. 


\section{Procedure description}

The present program was implemented in two primary public schools on the island of Crete and during the academic years 2013-2016. Throughout each year the specific program lasted 6 months. The program was implemented in 28 weekly sessions lasting 3 hours each that were separated into two phases- 1.5 hours at the beginning of the week and 1.5 hours at the end of the week (total 98 hours each academic year). Every session was coordinated by the teacher of general education of each particular group of pupils. The special education teacher was also responsible for taking photos, video shots and important notes of the pupils' activities. The other teachers were usually responsible for giving reports to the general education teacher on the final outcome of the program in each session of its implementation in and outside the classroom. In addition, the participant school directors (who applauded the program) made a great effort to build a trusting and collaborative atmosphere among the participating teachers and pupils and monitored the implementation of the program in terms of organization and ethics. Before, during and after the implementation of the program, the teachers with the support and guidance of a developmental psychologist worked closely to design, carry out, review and refine all the activities and materials included in the program. The program was executed parallel with the rest of the school activities.

Based on Kolb's idea (experience/action-learning/reviewexperimentation/further action) in each class, pupils worked together into mixed gender and mixed achievement level of 4 pupils ( 4 teams) to produce their own stories. This creative writing process involved the teams in searching together for story ideas, usually intrigued by the narration of their own personal experiences/representations. Therefore, at the beginning of each session, the teacher always stressed that "Our basic rule to begin is to hear what the other says, without offending him/her and without using racist 
or aggressive language against him/her". Additionally, questions reflecting the scope on resilience aspects and the role it plays in real life success, were used as such: Tell us/write about the person or hero you remember most based on your latest personal experience or in the story you/we read? Why? What challenge or dilemma did the character have to deal with? What personal strengths did the character possess in order to overcome his/her difficulties? What choices did he or she have to make? How did your character overcome his/her difficulties? How did other people support your character? Did your story have a good or a bad ending?

Then as a team (a coherent but not homogenous group) the pupils chose their fantasy heroes that reflected them, and integrated their ideas into a plan and worked to construct a story with vivid descriptions, interesting dialogues, cohesive and creative narratives, as well as the use of humour, suspense and drama. Once the children narrated a story or wrote a piece of it, they performed it.

At the end of the school year, all students became actors and actresses and performed their final story on stage with the participation of the whole learning community as well as a much broader audience.

\section{Data collection and analysis}

Data collection was based on: a) the videotaping of the whole group activities, b) the systematic observation of all children's behavior regarding their engagement in the activities and cooperation with the others (special emphasis was given in observing the students' with SEN active participation and interactions with their peers and teachers) and, c) the teachers' involvement in and acceptance of the program.

The teachers of general and special education monitored and took notes of all students' engagement and cooperation based on a series of criteria regarding: a) the quality of suggested ideas, and b) the number and quality of the students' interactions. 
Regarding the stories' content we did not proceed into a psychological evaluation or interpretation of the symbolic/metaphoric sense of the stories. From the video-recorded sessions of the project, the ones with the most representative and consecutive activities concerning the students' discourses/interactions, planning, writing and revising their stories were selected. Thematic analyses and illustrative extracts were used as a flexible approach for interpreting the present qualitative data and was conducted by the teachers of general and special education of each class, in cooperation with a developmental psychologist (Braun and Clarke, 2006; Marshall and Rossman, 2011).

\section{Findings presentation}

Based on the collected data codification and evaluation, the following remarks and indicative examples in each of the main areas of the program action are analyzed as follow:

(1) Cultivating group dynamics within the mainstream classroom through the creation of CoP- Levels of cooperation.

It was observed that enjoyment and active participation were two of the basic elements to develop among the students about a month after the implementation of the program. The following segment of dialogue (in the $3^{\text {rd }}$ grade of primary class) has been selected to illustrate the students' commitment and involvement through the expression of their thoughts/representations in a collaborative environment during the narrative process:

Teacher: So, we have agreed we will have these two characters, the scientist and the eagle, right? A girl responds: I still prefer the fairy with the long hair and her magic comb. Teacher: I believe you all agreed about the heroes, am I right? All teams: Yes! Teacher: Any way, we can keep in mind this possible heroine too and make a story about her. The same girl: Oh great, I'll think of a role for her in our story. Another boy says: Miss! The scientist reads all day...! An autistic student says: I study all day. 
Teacher: Do you mean that this hero looks like you? The autistic student: Oh yes miss! I want to be the scientist! Teacher: I would like you and the rest of the teams $(n 4)$ to think what makes the scientist and the eagle become good friends and devoted to each other? Please, think of one or two suggestions to discuss.

The above structured activity indicated how peer interactions helped the students with SEN to act socially and collaboratively within the general classroom. Teachers observed that the students with SEN were encouraged to become more socially interactive with their peers by learning how to produce and oppose the ideas proposed, to express emotions through their scenarios and heroes and engage in collaborative action with others. Autistic students seemed more oriented to the collaborative actions taking place in class than the other students with SEN/difficulties and seemed equally likely to be socially included as their non-SEN peers. However, the teachers indicated that through the narrative procedure "every student with SEN seemed to be more socially motivated to interact with their classmates and build their confidence by being part of the group. These students learnt to develop abilities such as how to discourse upon social issues and manage to reflect on their experiences in an enjoyable collaborative and interactive environment". The teachers also noticed that pupils without SEN found their peers with SEN quite entertaining especially when they narrated stories in the classroom or acted out roles (they were characterized as "funny" or "amusing" by their classmates) and were always preferred as playmates by their peers during the school's breaks.

(2) Students' learning about and expression of emotions through the narration and role-play of a personal or imaginary story.

A second segment of dialogue (in the $2^{\text {nd }}$ grade) illustrates the bad hero's emotional state in a difficult situation. It also represents the expression of emotion of a student 
with ADHD when telling a story (individual production) and the efforts of the teachers of drama and general education through careful questioning to help not only that student but all the students develop a sense of critical thinking about their expression of emotions (collective production). Role-play seemed quite helpful for students with emotional and behavioural problems to learn about their negative imaginative representations and to transform them into creative learning. The teacher observed the student(s) enter into a fictional world in order to assume roles that explored issues of a significant concern to them and to others:

Teacher: In the previous session we decided that the red dragon wants to cause problems to the blue dragon, right? The boy replies: Yes, because he is bad and I can become very bad too. Look at me I can spit fire everywhere (he starts doing that to the rest of the class). Teacher: Why would the red dragon act like that? The same boy: Because he is always angry. Now look how angry I am! Teacher: Can you think of another way of our hero doing that? (The boy stops and thinks). I would like you and the rest of the class to split into teams $(n 4)$ and think of not more than two ways of our red dragon expressing his anger to the blue dragon. Please think at least one adjective that describes the color and the sound of our red dragon's anger and write them down.

A closer examination of the students' interactions in the particular classrooms $\left(2^{\text {nd }}, 3^{\text {rd }}\right.$ and $4^{\text {th }}$ grade) showed that not all pupils and especially those with behavioural problems appeared to have the flexibility to work with their emotions, particularly when the setting included more kinetic/expressive motivations such as role playing. The teachers observed that these students seemed less confident in participating and tended to interfere pointlessly as if trying to disguise their emotional immaturity behind inappropriate behaviour. Gradually, the teachers indicated that there was a progressive decline in distracting/problematic behaviours due to the display of social rules and 
positive expressions of emotions through role-play. Both teachers noted that "students learn social rules or positive expression of emotions from watching others' doing so". Particularly, the drama teacher stated that if a student acted in a way that was inappropriate or appropriate, there was usually an immediate respond by the rest of the group, either negatively or positively. "Role-play surrounded the student's negative emotional state and reconstructed it in a meaningful/interactive way of social behaviour and emotional exchange". Finally, the art teacher noted that drawing their heroes or parts of their story, gave students with hyperactivity/behavioural problems the opportunity to ventilate feelings of anger or frustration and be involved in higher levels of symbolic expression and mentality.

(3) The progressive inclusion of children with SEN in the general classroom/group and respect of diversity through the written construction of their story. This part of this story deals with the developing of relationships and the matter of friendship and diversity. Investigating the pupils' interactions in all three classrooms, a tendency was detected for children with SEN (especially for the autistic ones) to be "looked after" and supported by their non- SEN peers when working together with their ideas and then writing them down. This finding emerged (before writing down thoughts and feelings) through the narration and role-play of an upcoming event in the pupils' story in the $3^{\text {rd }}$ grade- a sick bird, an eagle that falls into a long sleep. For the role, a student with autism was unanimously elected to play the protagonist of their final written story.

The teacher said: Before writing down our thoughts and feelings about the two friends' situation, we are going to re-enact the moment when our protagonist "the scientist" saw his devoted friend "the eagle" lying unconscious on the ground. How does the scientist feel about not being able to wake his best friend up? A girl replied: I 
am sad because the eagle might die. A boy started shaking the autistic pupil who played the eagle: Wake up, wake up! Another girl said: I wish he would wake up from his long sleep. Another boy continued: I'm sure the scientist is bored now without him. The teacher: What does he miss most about him? The children volunteered suggestions such as, 'He made him laugh', 'He was kind to him' and 'He liked him because he was different from him'. The teacher probes: How was he different? Several children commented on his size (the eagle was big) or the bird's abilities (a bird can fly while a human cannot). And so the discussion went on.

Discourses and role playing upon the issue of diversity before writing of stories about their fictional heroes proved very helpful for the participant teachers for setting the pace and meeting the educational and socio-emotional needs of each student, without including the need to differentiate their instruction or face the possibility that some students may be overlooked. The teachers noted that "learning became a collective process" and that each student demonstrated the capacity to learn as all students were kept engaged despite their differences in how slowly or quickly they learned new material. The teacher of special education reported her satisfaction with how supportive and helpful all the students were to each other, as most students with SEN experienced difficulty when writing their stories, students without SEN seemed eager to help them. It seems that the combination of their thoughts and feelings for choosing and writing of a common scenario of their final story helped most of the students with and without SEN cultivate stronger relationships and supported inclusion in the general classroom.

(4) Building resilience and socio-emotional skills in students such as empathy, selfawareness and self-regulation. 
The following monologue concerns the students' imaginary hero who can't help his friend the eagle. The particular monologue was written by a boy in the $4^{\text {th }}$ grade who incidentally had to put up with his parents' divorce and the coming birth of a new baby. This monologue became a part of the students' final story and represents an example of self-regulatory technique and problem solving that pupils were encouraged to demonstrate in a difficult situation.

Oh Lord! What happened to my beloved eagle? He won't wake up! What happened to him! If he doesn't wake up, I will lose my best friend and devoted companion. Oh no! I will be all alone! What else can I do to help him? I have tried everything but nothing happens. No, no, I won't give up! I won't leave him helpless. He is my friend and if someone really loves and cares for somebody they always come up with the right solution. Yes, yes that's it! I think I've got it!

Narrating, performing and writing similar monologues (individual productionlearning/review) seemed to help all the students, particularly those with socio-emotional problems to reflect on what they were experiencing in their everyday interactions/relationships with their significant others (parents, siblings, friends, teachers). This technique enabled them to explore in a collaborative spirit (collective production-experimentation/further action) the ways in which they would cope with their emotions/reactions, both rational and irrational.

(5) Teachers' involvement in the program Teachers who participated in the 3-year program (5 each year) seemed quite enthusiastic about implementing similar collaborative programs as a medium to teach new ideas within the school context. At the beginning, most teachers participating approached the program with some trepidation, but by the end of the program the teachers of general and special education stated that all the students achieved something 
and learnt something new and that "they can use what they have learnt in a different way based on their experience through their collective engagement with each other". The drama teacher experienced "a personal development" and the teacher of special education reported that through the implementation of such programs "children prepare for life and cope with growing up". Additionally, the art teacher stated that "Such programs allow children to explore and make sense of the complexities of life without experiencing failure" and the school director agreed that "the particular program became the connection that helped children and adults learn at their best".

The participating teachers shred their new teaching experiences with the non participant ones, and all agreed that "It is the school's responsibility to provide teachers with the appropriate professionals in order to guide them to be involved in new teaching environments and practice more innovative methods that promote a collaborative spirit among the teaching staff, students and their families".

\section{Discussion}

Based on the inclusive education and resilient $\left(6^{\text {th }}\right.$ wave) theory perspective, the scope of the present attempt was to activate and meaningfully engage both students (with and without SEN) and their teachers in a common goal and action: the (co)production of knowledge through storytelling, role-play and creative writing within the mainstream classroom (Chan, 2013; Nezami et al. 2017; Shapiro et al. 2012; Kilgour et al. 2015; Stockwell, 2016). The activation/stimulation of a series of basic social-emotional skills which are indispensable for working and functioning in community was considered important as well (Kourkoutas et el. 2015).

For this, an additional aim was to create a kind of Community of Practice (Wenger, 2006), a lively group of students with its own dynamic and collaborative 
character (not different from the other traditional classrooms of the Greek educational system), which are teacher-centred and highly competitive (Zoniou-Sideri et al. 2006).

According to the findings, the active contribution of the students' stories which were meaningful and useful in the final production as a collective story created an atmosphere that aimed at teaching positive social behaviours such as empathy, selfawareness and self-regulation (Chan, 2013; Fagan, 2010). This is a basic principle, both in inclusive education and resilience theory, as it was found that supportive relationships with adults and peers is one of the most critical factors in overcoming adversity and developing a student's own potential (Ainscow et al. 2012; Kourkoutas et al. 2017). From a joint perspective, the students with SEN were given the opportunity to co-operate/engage with others and their teachers and being creative and inventive in storytelling, acting/performing and writing (Ainscow et al. 2012; Wenger, 2006).

In terms of how children with SEN benefited from the implementation of the present program, this study found that social-emotional development mostly outweighed academic achievement. The teachers in this study, by organizing the curriculum around such activities/interventions appeared quite contented to see the majority of students and especially the ones with SEN engage in a collaborative academic learning (according to their level of ability of course). Though, the emphasis was finally given on the development of social-emotional skills, empathy, selfawareness and self-regulation rather than academics (Nezami et al. 2017).

The participant teachers gave the opportunity to all the students and especially to students with SEN, who seemed to be very reluctant and socially more shy or withdrawn, to talk about themselves through their stories or allow themselves to have a more active role in the group. This was probably due to the very trustful, intimate and confidently easy-going group atmosphere (Waters et al. 2015). A trustful and supportive 
environment that ensured students' feeling of exposing themselves (thoughts and weaknesses or deficits and intimate feelings which would not be ridiculed or denigrated, and certainly not excluded) allowed them to talk more freely (Fagan, 2010; Nezami et al. 2017; Stockwell, 2016).

From an academic point of view, the students' diversity of imaginative discourses/dialogues and the sophistication of the language they learnt to use became the tools for communicating/negotiating with one another and self-expression. By performing the children's bodies, minds and emotions became extremely active and (Magos et al. 2008; Shapiro et al. 2012), students made connections between their previous experiences and the imaginative and acted as one would in the inventive situation (Nezami et al. 2017; Kilgour et al. 2015).

Findings revealed that students without SEN took on more of a caring role towards the vulnerable student, which was really activated by working together with their ideas and then writing them down (Evins, 2015). Despite the tendency of pupils with SEN to be more disruptive or withdrawn at the beginning of the program, during the course they were encouraged to transform themselves by developing emotions and motor skills. Activities that involved physical play seemed to help them take control over their negative emotions (Kilgour et al. 2015; Moore, 2004). These students were likely to better control such emotions when they enacted them into role playing activities, as they became able to structure their disturbing emotions and find symbolic/metaphoric ways to express them, under the guidance of experienced professionals (Makoelle et al. 2015; Zins et al. 2006).

The professional "mentoring" and supporting guidance seemed critical to help teachers to be more positive and inventive in facilitating the children with difficulties to develop their own capacities and thus be more easily accepted by the rest of the students 
(Kourkoutas et al. 2017; Waters et al. 2015; Zins et al. 2006). Probably due to the developmentally suitable nature of the activities that seemed to address children with or without SEN basic social-emotional needs and expectations, the students of the present study became easily engaged in this project, (Putman, 2009; Waters et al. 2015).

Given that the Greek school curriculum is mostly cognitive-centred and does not give enough emphasis on student's socio-emotional development (Zoniou-Sideri et al. 2006), the present program devoted many meetings to oral, role-play and written sessions on conflict resolution, cultural difference, and cooperation. Many of the children (with or without SEN) were not used to reflecting or taking part in such kind of activities or work on these topics. The combination of talking, exchanging ideas orally, role-play and writing in the particular student group, although not noticeably different from other typical Greek classrooms, became a significant resilient skill-building tool which seemed to help students develop positive social behaviours such as confidence and understanding of others (Putman, 2009; Waters et al. 2015).

The present finding is in agreement with other findings which argue that a supportive and collaborative school environment (enhancing positive interactions between teachers and students, reflecting warmth and a lack of anger and hostility) (Wenger, 2006), may positively affect both students' capacity to relate to others and creative and productive learning in the most vulnerable ones (Ainscow et al. 2012; Kourkoutas et al.; Putman, 2009). It is worth mentioning that by the end of the year the majority of children were more related, socially competent, more attentive, and less aggressive than in comparison with their peers in other classrooms.

The above findings confirmed the researcher's perception that there is still a lot more work to be done in order for the Greek schools to provide a different environment for their students (with or without SEN) and instill confidence among teachers to 
develop innovative techniques and teaching methods that promote inclusion and resilience.

\section{Conclusions}

Schools should undertake a fundamental role in the development of children's socioemotional health by promoting skills such as self-awareness, empathy and collaboration. The implementation of such prevention programs relates to the organization of the school, as well to the teachers' ideology, and to relationships with students. The appropriate inter-professional guidance will enable teachers to explore their attitudes towards such new learning ideas and will support them into introducing changes in their schools.

Moreover, given that the Greek curricula and the educational community culture highly prioritize a system where individualism and academic standards (performance) are highly invested in and awarded, most teachers recognize the value and also the efficacy of such methods to mobilize students and activate their creative and reflective skills (a fundamental goal in all contemporary educational systems) (Zoniou-Sideri et al. 2006).

Overall, storytelling, role-play and creative writing seemed to be the most attractive educational methods to produce changes in children, teachers, and classroom dynamics and functioning (Kourkoutas et al. 2017). Still though, a more extended mobilization of the educational community is required for the cognitive-centred Greek educational system.

Certainly, more multidimensional methodology-based research is needed in order to understand how relationships among pupils and teachers are cultivated and to change perceptions or inherent negative dynamics, in schools in order to facilitate the 
development of collaborative projects that build environments which respect diversity and promote resilience and solidarity.

\section{References}

Ainscow, M., Dyson, A., Goldrick, S. and West, M. 2012. "Making Schools Effective for All: Rethinking the Task". School Leadership \& Management, 1-17. doi.org/10.1080/13632434.2012.669648.

Braun, V. and Clarke, V. 2006. "Using Thematic Analysis in Psychology". Qualitative Research in Psychology, 3 (2): 77-101. doi.org/10.1191/1478088706qp063oa.

Bruner, J. 1997. Praxis Noimatos [Making Sense through Action]. Athens: Ellinika Grammata.

Chan, Z. C. Y. 2013. "Role-playing in the Problem-based Learning Class". Nurse Education in Practice, 12 (1): 21-27.

Evins, E. A. 2015. "The Effects of Inclusion Classrooms on Students with and Without Developmental Disabilities: Teachers' Perspectives on the Social, Emotional, and Behavioral Development of All Students in Inclusion Classrooms”. Doctoral Papers and Masters Projects. 31. http://digitalcommons.du.edu/capstone_masters.

Fagan, D. 2010. "Creative Writing Creating Community: The Power of the Personal". Creative Writing: Teaching Theory \& Practice, 2 (2): 147-161. http://www.cwteaching.com.

Ferguson, R. 2012. “Let's Find a Way to Learn About our Rights”. In Safe Spaces. Human Rights Education in Diverse Contexts, edited by C. Roux, 131-150. Amsterdam: Sense Publications.

Goode, W. J. and Hatt, P. K. 1986. Methods in Social Research. McGraw Hill Book coSingapore. 
Hill, C. E., Knox, S., Thompson, B. J., Williams, E.N., Hess, S. A. and Ladany, N. 2005. “Consensual Qualitative Research: An Update". Journal of Counseling Psychology, 52 (2): 196-205.

Khalnou, N. and Wray, L. 2014. "A Whole Community Approach toward Child and Youth Resilience Promotion: A Review of Resilience Literature”. International Journal of Mental Health Addiction, no. 12: 64-79.

Kilgour, P., Reynaud, D., Northcote, M. and Shields, M. 2015. "Role-Playing as a Tool to Facilitate Learning, Self Reflection and Social Awareness in Teacher Education”. International Journal of Innovative Interdisciplinary Research, 2 (14): 8-20.

Kolb, D. 1984. Experiential Learning. NJ: Prentice Hall.

Kourkoutas, E. E., Hart, A., Graaf, U. and Kassis, W. 2017. “A Resilience-based Program to Promote Reflective and Inclusive teaching Practices in Greece during Austerity". In Teacher Professional Knowledge and Development for Reflective and Inclusive Practices, edited by I. H. Amzat and N. V. Valdez. London: Routledge.

Kourkoutas, E. E., Vitalaki, E. and Fowler, A. 2015. "Resilience Based Inclusive Models for Students with Social-emotional and Behavioral Difficulties or Disabilities". In Innovative Practices for Children and Adolescents with Psychosocial Difficulties and Disabilities, edited by Authors, 8-45. Cambridge Scholar Publications.

Makoelle, T. M. and Malindi, M. 2015. "Resilience: A Framework for Inclusive Pedagogy in a South African Context". Electronic Journal for Inclusive Education, 3 (3): 1-16. http://corescholar.libraries.wright.edu/ejie.

McNiff, J., Lomax, P. and Whitehead, J. 2003. Your and Your Action Research Project (second edition). London, Routledge. 
Magos, K. and Politi, F. 2008. "The Creative Second Language Lesson: The Contribution of the Role-play Technique to the Teaching of a Second Language in Immigrant Classes”. RELC Journal, 39 (1): 96-112.

Marshall, C. and Rossman, G. B. 2011. Designing Qualitative Research (5th ed.). USA: Library of Congress Cataloging-in-Publication Data.

Mills, G. 2003. Action Research: A Guide for the Teacher Researcher, $2^{\text {nd }}$ ed. Upper Saddle River, NJ: Merrill/Prentice Hall.

Moore, M. M. 2004. "Using Drama as an Effective Method to Teach Elementary Students”. Senior Honors Theses. $113 . \quad$ http:// DigitalCommons@EMU:http://commons.emich.edu/honors/113.

Nezami, H., Barekat, B. and Tahriri, A. 2017. "The Effect of Drama Method and Dramabased Activities on Iranian Pre-intermediate EFL Learners' Speaking Skill”. International Journal of Research Studies in Language Learning, 7 (2): 79-91. doi:10.5861/ijrsll.2017.1762.

O'Hanlon, C. 2003. Educational Inclusion as Action Research: An Interpretive Discourse. Maidenhead, UK: Open University Press.

Putnam, J.W. 2009. “Cooperative Learning for Inclusion”. In Psychology for Inclusive Education: New Directions in Theory and Practice, edited by P. Hick, R. Kershner, and P. Farrell: 81-95. Abingdon: Routledge.

Shapiro, S. and Lepopold, L. 2012. "A Critical Role for Role-Playing Pedagogy”. TESL CANADA JOURNAL/REVUE TESL DU CANADA, 29 (2):120-130. doi.org/10.18806/tesl.v29i2.1104.

Stockwell, R. 2016. "Creative Play: Welcoming Students into a Community of Practice in Creative Writing through a Participatory Action Research Project". New 
Writing: The International Journal for the Practice and Theory of Creative Writing, 13 (2): 261-272. doi.org/10.1080/14790726.2016.1142569.

Vygotsky, L.S. 1978. Mind in Society. Cambridge: Harvard University Press.

Waters, L., Barsky, A., Ridd, A. and Allen, K. 2015. "Contemplative Education: A Systematic, Evidence-Based Review of the effect of Meditation Interventions in Schools". Education Psychological Review, 26 (1). doi.org/10.1007/s10648-0149258-2.

Wenger, E. 2006. "Communities of Practice”. International Encyclopedia of the Social \& Behavioral Sciences, 2339-2342. doi.org/10.1016/B0-08-043076-7/00361-2.

Zins, J. E., and Elias. M. J. 2006. "Social and Emotional Learning: Promoting the Development of All Students". Journal of Educational and Psychological consultation, 17 (2\&3): 233-255.

Zoniou-Sideri, A. and Vlachou, A. 2006. “Greek Teachers' Belief Systems about Disability and Inclusive Education”. International Journal of Inclusive Education, 10 (4/5): 379-394. doi: 10.1080/13603110500430690. 